\title{
Mobile Phone and Family Happiness, Mediating Role of Marital Communication: An Attachment Theory Perspective
}

\author{
https://doi.org/10.3991/ijim.v15i21.17811 \\ A. Akrim ${ }^{1(\bowtie)}$, Juhriyansyah Dalle ${ }^{2}$ \\ ${ }^{1}$ Universitas Muhammadiyah Sumatera Utara, North Sumatera, Indonesia \\ ${ }^{2}$ Universitas Lambung Mangkurat, South Kalimantan, Indonesia \\ akrimeumsu.ac.id
}

\begin{abstract}
Mobile phone communication has established itself as an essential element of people's personal and working lives. Thus, it has become a significant connection for the most intimate form of interpersonal relations, including marital relationships. Based on the attachment theory perspective, this research highlights the importance of mobile phone usage and its influence on marital communication's life satisfaction and family happiness through the underlying mechanism of marital communication. Using a short cross-sectional field survey, data from 120 respondents were collected. The target sample was married partners, staff, or students, each possessing a mobile phone in the stateowned universities in South Kalimantan and North Sumatera, Indonesia. Data were further analyzed using SmartPLS3. The results revealed that mobile phone usage was positively associated with martial communication that further resulted in satisfaction with life and family happiness. Hence, based on the attachment theory perspective, the communication with the spouse results in maintaining a robust intimate relationship by keeping in touch, sharing updates, emotions, feelings, knowing about children, and ensuring each other's safety through using a mobile phone. The findings showed a significant need for continued communication in a marital relationship, especially using the fastest and most comfortable means. Given the synchronous nature of mobile phone communication, current research provided multiple insights and avenues of future exploration for social scientists in this Information Society, where we need updates from our spouses, children, friends, and the situation at large.
\end{abstract}

Keywords - mobile phone, marital communication, interpersonal relationships

\section{Introduction}

Mobile phone communication has established itself as an element of 'human's personal and working lives. Thus, it has become significant for interpersonal relationships' most intimate form: the marital relationship [1]. Nowadays, it is ubiquitous for couples to keep connected through a short-medium of mobile phone technology [2]. Couples communicating through technology get the ease and benefit of swift coordination, allowing them to correspond to all sorts of circumstances or crises [3]. 
Also, married couples can share their feelings, emotions, and thoughts more frequently because of this technology, leading their relationship towards an efficient and attentive progression [4]. Sometimes, couples are reluctant to communicate face-to-face, especially in self-disclosure moments, and feel more convenient to interact through this medium, which also evolves them into closer relationships [5]. Likewise, the study of mobile phone communication, in general, has been mushrooming in the past and recent years $[6,7,8]$.

Consequently, a long-standing question for technology researchers concerns whether increasing reliance on technology strengthens or weakens social ties $[9,10]$. Although most of the past studies have focused more on the negative impact of using mobile phones [11,12], some studies reveal mobile phone usage among married couples as an effective and successful way of communication. These findings further anticipate that it does not necessarily mean that mobile phone usage among couples could only have negative consequences [13], therefore the current study has opted for the positive side of the use of mobile phone among married couples for marital communication, which further evolves into satisfaction with life and family happiness. The nature of attachment and attachment style between two partners greatly influences the marital relationship. Therefore, in the case of married partners, each spouse is an attachment figure of the other, which can be seen from their communication styles. Similarly, [14] demonstrated that mobile technology's advent facilitated us to create specific communication patterns in close relationships, referred to as the connected mode of communication. Therefore, the attachment theory guides the present study to explain the importance of mobile phones and marital communication.

Most of the existing studies did not thoroughly examine the importance of mobile phone communication in marriage. However, they looked at those partners' aspects, still dating but not yet married. Simultaneously, the study results on mobile communication among married partners in the rich Eastern and Asian cultural context of Indonesia could differ from those of the dating process partners based on the attachment styles and intimacy that develops via marital relationship. Thus, the current study has aligned its proposed model with the attachment theory, advancing to existing literature related to technology and social theories [15]. It suggests strengthening couples' bond through marital communication by using a mobile phone and investigating how mobile phone communication supports the marriage relationship. Therefore, on the grounds of attachment theory, the current study aims;

1. To understand the positive association of mobile phone use on satisfaction with life and family happiness among married couples in the Indonesian cultural context.

2. To suggest the underlying mechanism of marital communication between mobile phone usage and positive outcomes like satisfaction with life and family happiness.

\section{Theoretical background and hypothesis development}

\subsection{Attachment theory}

The Attachment theory was extended to adult romantic relationships in the late 1980s by Cindy Hazan and Phillip Shaver. The attachment means an affectional bond or tie 
between an individual and an attachment figure (usually a caregiver) [16]. According to [17], [18], four adult attachment styles can be recognized by keeping into consideration the internal working model of close attachment. These styles include dismissing, possessive, fearful, and secure based on someone's image of his/her partner. All levels of relationships can get influenced by the attachment style. Therefore, it wields a substantial impact on the communication between the partners. It is assumed that attachment style also influences mobile communication in couple relationships. One of the technical features of mobile communication is being accessible independent of time and location. [8] argue that, across cultures, communication tools are used by the people to maximize their confirms and needs, which resulted in new means of interaction among them.

The influence of attachment style can be postulated in all levels of the relationship, hence impacting the communication between the partners. For instance, it has been empirically demonstrated that securely attached persons relate more frequently and intimately with their partners than dismissing attachment types. It is assumed that attachment style also influences mobile communication in couple relationships. Being reachable independent of time and location, for instance, is an inherent technical feature of mobile communication. However, it must be implemented concerning the partner (partner taking the cell phone with him/her, turning it on, answering calls). The attachment theory guides the present study to explain the importance of mobile phones and marital communication. Katz and Aakhus [19] argue that, across cultures, people use communication tools in ways that maximize their needs and comforts, often resulting in the invention of new ways people interact. Similarly, [18] demonstrated that mobile technology's advent enabled us to develop a particular communication pattern in close relationships, referred to as the 'connected mode of communication.

\subsection{The association of mobile phone use with the satisfaction with life, family happiness and marital communication}

Prior studies suggest that incorporating technology in daily life routine, specifically in relationship maintenance and coordination among partners, is beneficial [7,20]. Some studies indicate that individuals who communicate through multiple media such as cell phones and emails have stronger family relationships than those who communicate only face to face [8]. [21] His study revealed that technology enables families to remain connected, and they can share their matters over mobile phones as smartphones have replaced computers in many ways, like gaming and educational apps [22]. Literature reveals that individuals in romantic relationships used mobile phones significantly more often than those not romantically involved [8]. The use of technological devices like smartphones for communication has become a significant part of' 'everyone's lives $[13,14]$. It helps them connect and interact with their better half to build up further and bolster their marriage [23] by better life connection. Thus, it can be argued that through mobile phone communication, people can strengthen their family bonds, build mutual support, which ultimately strengthens their bond and does not make them feel alone or neglected, further leading towards family happiness. Expectedly bringing more satisfaction and connected communication with joy in the family. Hence, the following hypotheses are suggested; 
H1: Use of mobile phone is positively associated with satisfaction with life among married couples

H2: Use of mobile phone is positively associated with family happiness among married couples

H3: Use of mobile phone is positively related to marital communication among married couples

Strong marital communication among married couples invigorates satisfaction with life and reinforces family happiness. Scholars have named this ease of access with a mobile phone as an immediate and convenient interaction [24]. This allows couples to collaborate and keep in touch as smartphones allow communicative techniques and multidimensional methods [25]. Therefore, it is argued that well-established marital communication is expected to lead to a satisfied and happy life. Conclusively, the following hypotheses are suggested;

H4a: Marital communication is positively associated with satisfaction with life among married couples

H4b: Marital communication is positively associated with family happiness among married couples

\subsection{Mediation}

Researchers observed that satisfaction comes when the couples frequently stay connected to each other, and their 'texting pattern or attitude equates to each other [11]. This suggests that a longer relationship exists between married couples when they are frequently keeping in touch, which is more effective by using a medium that makes it possible in an effective way, i.e., a mobile phone. Moreover, [13] suggested that the relationship between satisfaction and closeness increases in couples with active communication among them through smartphones. On the other hand, technological advancements have now made it possible to communicate in ways that were never possible before, such as covering up long-distance relationships [4]. This further reveals the importance of marital communication among married couples through mobile phones and further showing towards the path of happiness and happy life, as this technology reduces long distances. Because a mobile phone facilitates the marital bond a level of closeness and strength [26], which leads to a happy life. Therefore, based on attachment theory, improved communication between married couples through a communicative device such as a mobile phone is expected to lead towards more happiness and satisfaction in life. Hence, the following hypotheses are suggested;

H5: Marital communication mediates the relationship between mobile phones and satisfaction with life among married couples.

H6: Marital communication mediates the relationship between mobile phones and family happiness among married couples. 


\subsection{Theoretical framework of the study}

Based on introduction and theoritical background and hypotheis development, then the theoretical framework of the study can see on Figure 1.

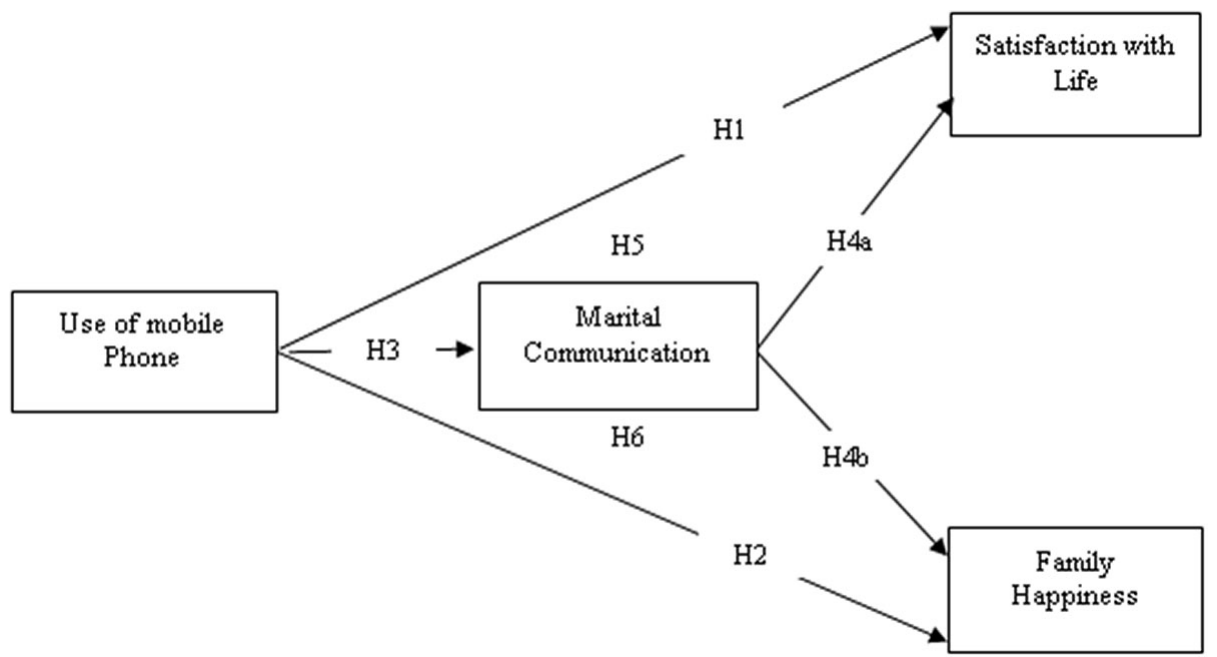

Fig. 1. The theoretical framework of the study

\section{$3 \quad$ Methodology}

Using a short cross-sectional field survey, data from 120 respondents were collected. The target sample was married partners, each possessing a mobile phone, staff, or students who can fully understand the survey language English, in one of the stateowned universities in South Kalimantan and North Sumatera, Indonesia. After ensuring a pre-conditions convenience random sampling technique was used, the study's purpose was briefed, and anonymity was guaranteed to seek voluntary participation. In total, 170 questionnaires were distributed, and 141 were received back, which were further scrutinized, and 21 more responses were excluded from data. A total of 120 responses was analyzed with a final response rate of $70.58 \%$. The male \& Female respondents were 50 percent; equally, nationals accounted for the highest number of respondents (70\%); the age-group of 26-32 years old reported the highest percentage of 53.3, followed by ( 33 years \& above) with 40 percent and 19-25 years with 6.7 percent. The spouses with 1-3 years dominated the sample with 40 percent, followed by (more than seven years) with 33.3 percent. Spouses staying together accounted for 60 percent, while those in long-distance relationships were recorded as $40 \%$. Spouses who have used the mobile phone for 1-3 years reported a higher percentage of $43.3 \%$ compared to others.

The mobile phone use was measured using three statements adapted from [27] with the scale ranging from never to frequently. Family happiness was measured with a 
15-items scale based on 5 statements adapted from the Oxford Happiness Questionnaire (OHQ) [28] on a 5-point Likert scale ranging from " $1=$ strongly disagree" to " $5=$ strongly agree". Marital Communication was measured using a 10 -item scale adapted from [29]. The Satisfaction with Life Scale was measured using a 5-item scale adapted from [30].

\section{Data analysis and results}

Statistics, correlation analysis, and one-way ANOVA to find out the information about control variables. ANOVA results revealed that age and period in marriage significantly affected the dependent variable; therefore, both were controlled during further analysis. To test the current study's hypotheses, PLS-SEM (Partial Least Square-Structural Equation Model) in SmartPLS version 3.2.8 was used [31,32,33]. This study has focused more on PLS-SEM as compared to CB-SEM (Covariance Based-Structural Equation Model). It can predict more than one dependent variable and is mostly used for theory development. As the sample of this study is small $(n=120)$. Therefore, PLS-SEM is considered appropriate for a small sample size. This approach consists of two steps. In the first step, we test the measurement model, and in the second step, we analyzed the structural model.

The measurement model was further evaluated based on validity and reliability. It includes individual and composite reliability verified through factor loadings ( $\lambda$ must be greater than 0.7) and Cronbach's alpha values that must be greater than 0.6 or 0.7 $[34,35]$. The values of Cronbach's alpha values and composite reliability are beyond the critical values $(0.6$ or 0.7$)$, indicating the reliability of constructs. Convergent validity verified through AVE (Average Variance Extracted) that should be more than 0.5 . In the current case, the AVEs values are above 0.5, suggesting that items are valid [36]. Discriminant validity also comes under the assessment of the measurement model. To check the discriminant validity, the square root of the AVE of every construct in the model must exceed the correlation between the constructs [37]. All the values of reliability and validity are in range and given in Table 1.

Table 1. Factor loadings, reliability, and validity

\begin{tabular}{|l|c|c|c|}
\hline \multicolumn{1}{|c|}{ Constructs } & AVE & CR & 'Cronbach's $\boldsymbol{\alpha}$ \\
\hline Mobile phone use & 0.663 & 0.855 & 0.765 \\
\hline Marital Communication & 0.531 & 0.832 & 0.858 \\
\hline Satisfaction with Life & 0.708 & 0.924 & 0.897 \\
\hline Family Happiness & 0.709 & 0.925 & 0.890 \\
\hline
\end{tabular}

Note: CR, composite reliability; AVE, average variance extracted.

The HTMT values are also used for discriminant validity, and it should be $\leq 0.85$. shown in (Table 2 and Figure 2), the values of HTMT are lower than $\leq 0.85$ indicating the validity of items [32]. 
Table 2. Heterotrait-Monotrait ratio

\begin{tabular}{|l|c|c|c|c|c|c|}
\hline \multicolumn{1}{|c|}{ Constructs } & Mean & STD & $\mathbf{1}$ & $\mathbf{2}$ & $\mathbf{3}$ & $\mathbf{4}$ \\
\hline Mobile phone Use & 3.78 & 0.71 & 0.814 & & & \\
\hline Marital Communication & 4.01 & 0.55 & 0.469 & 0.728 & & \\
\hline Satisfaction with life & 3.99 & 0.53 & 0.421 & 0.350 & 0.841 & \\
\hline Family Happiness & 3.91 & 0.62 & 0.358 & 0.440 & 0.380 & 0.842 \\
\hline
\end{tabular}

Note: The square roots of AVEs of the constructs are shown in bold in diagonal.

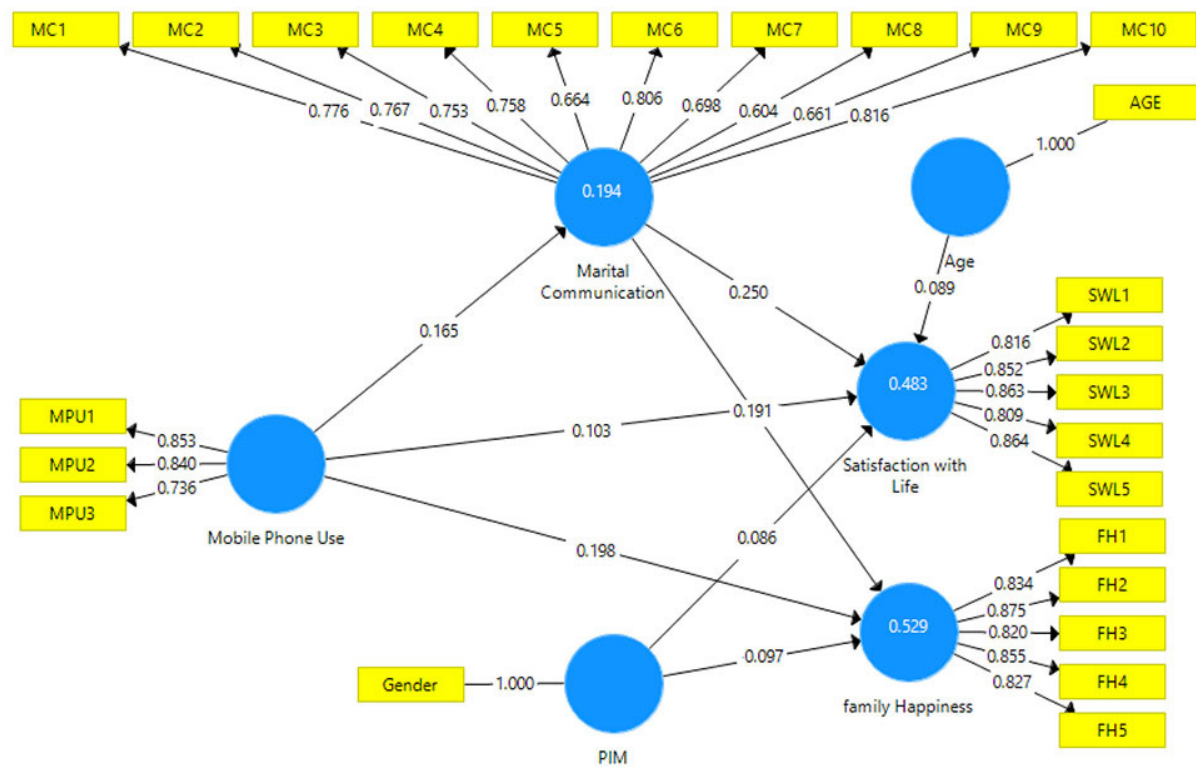

Fig. 2. Measurement model

In analyzing the structural model, the Bootstrapping procedure was used with 120 sample size. The results of this study show there was a significant positive association of mobile phone use with life satisfaction $(\beta=0.103 * *, t=2.533)$, family happiness $\left(\beta=0.198^{* * *}, \mathrm{t}=4.237\right)$, and marital communication $\left(\beta=0.165^{* * *}, \mathrm{t}=3.866\right)$. Therefore, hypotheses $H 1, H 2$, and $H 3$ were accepted. Likewise, the association of marital communication with life satisfaction $\left(\beta=0.250^{* * *}, \mathrm{t}=5.891\right)$ and family happiness $\left(\beta=0.191^{* * *}, \mathrm{t}=4.108\right)$ was positive and significant, thus proving the $\mathrm{H} 4 \mathrm{a}$ and $\mathrm{H} 4 \mathrm{~b}$. Finally, the indirect effect of mobile phone use with life satisfaction $\left(\beta=0.151^{* *}\right.$, $\mathrm{t}=3.099)$ and family happiness $\left(\beta=0.224^{* * *}, \mathrm{t}=5.187\right)$ via martial communication was found significant thus, $H 5$ and $H 6$ both were supported (See Table 3 ). 
Table 3. Hypothesis testing results

\begin{tabular}{|l|l|c|c|c|l|}
\hline \multicolumn{2}{|c|}{ Hypothesized Paths } & Std. Beta & t-value & p. value & \multicolumn{1}{|c|}{ Findings } \\
\hline H1 & MPU $\rightarrow$ SWL & 0.103 & 2.533 & 0.010 & Supported \\
\hline H2 & MPU $\rightarrow$ FH & 0.198 & 4.237 & 0.000 & Supported \\
\hline H3 & MPU $\rightarrow$ MC & 0.165 & 3.866 & 0.001 & Supported \\
\hline H4a & MC $\rightarrow$ SWL & 0.250 & 5.891 & 0.000 & Supported \\
\hline H4b & MC $\rightarrow$ FH & 0.191 & 4.108 & 0.000 & Supported \\
\hline H5 & MPU $\rightarrow$ MC $\rightarrow$ SWL & 0.151 & 3.099 & 0.010 & Supported \\
\hline H6 & MPU $\rightarrow$ MC $\rightarrow$ FH & 0.224 & 5.187 & 0.000 & Supported \\
\hline
\end{tabular}

Note: $\mathrm{MPU}=$ Mobile Phone Use, $\mathrm{SWL}=$ Satisfaction with Life, FH = Family Happiness MC $=$ Marital Communication.

\section{Discussion and implications, limitations and future research directions and conclusion}

The positive association of mobile phone usage with marital communication, satisfaction with life, and family happiness are in line with the results of [21]. Likewise, the findings suggest that mobile phones provide and facilitate the marital bond as a level of closeness and strength [24], which leads to a happy life. As previous research has stated, coordinated activities among partners, a symbol of relationship maintenance which depicts close bonding among them [16,38], is a secret of living a happy life. Besides, 'respondents' reasons for communicating with a spouse using a mobile phone could be summed as; keeping up with updates, sharing feelings and emotions, strengthening the relationship, knowing about the children, keeping closer, sharing each 'other's problems and difficulties, e.g., about studies, it is the easiest way to communicate (you can get immediate feedback). Seeking attention and responding to others' care is an essential means of maintaining relationships. The mobile phone comes in handy as a crucial tool for managing engagement [20,34].

Further, it can be stated that marital communication via mobile phones strengthens marriage by knowing each other's worries and fears to understand each other $[39,40]$ better. Moreover, this study findings have revealed significant results that concluded that mobile phone integration into married couples is a must to strengthen their bond with each other and generate a good and happy life. Academically this study contributed to the existing literature by analyzing the positive association that a mobile phone can have in a married couple's life through marital communication. Also, this study has an integrated theory of attachment in the marital context. Practically, in real life, this study highlighted the vital role of mobile phone usage $[41,42,43]$ in marital communication covering up various aspects in human life, i.e., emotional sharing even distant, reminding each other of chores, and task sharing, etc. This research has contributed to the body of knowledge in several ways, such as a unique contribution to literature related to the research's mobile phone stream.

A rare study integrating human interaction attachment theory into mobile phone studies and family happiness and satisfaction studies. A novel contribution to Eastern 
Indonesian cultural context where marriage has a different contextual condition than Western studies. An advance to the current body of knowledge by hypothesizing and confirming marital communication mediation between mobile phone use based on attachment theory and its outcomes. This research provided several insights for future scholars to investigate the model in a more significant sample with a longitudinal study design for better generalizability as a cross-sectional design, and low data sample are significant limitations of this research. Multiple mediating and moderating variables are recommended to be explored between mobile phone use and its outcomes.

\section{Acknowledgment}

The authors are grateful to the Rector of Universitas Muhammadiyah Sumatera Utara and Rector of Universitas Lambung to support this research collaboration with self-funding.

\section{$7 \quad$ References}

[1] David, M. E., Roberts, J. A., \& Christenson, B. (2018). Too much of a good thing: investigating the association between actual smartphone use and individual well-being. International Journal of Human-Computer Interaction, 34(3), 265-275. https://doi.org/10.1080/10 $\underline{447318.2017 .1349250}$

[2] Doring, N., \& Dietmar, C. (2003). Mediated communication in couple relationships: Approaches for theoretical modeling and first qualitative findings. Forum: Qualitative Social Research, 4(3), 1-17. http://dx.doi.org/10.17169/fqs-4.3.676

[3] Utz, S. (2015). The function of self-disclosure on social network sites: Not only intimate but also positive and entertaining self-disclosures increase the feeling of connection. Computers in Human Behavior, 45, 1-10. https://doi.org/10.1016/j.chb.2014.11.076

[4] Hertlein, K. M., \& Chan, D. (2020). The rationale behind texting, videoconferencing, and mobile phones in couple relationships. Marriage \& Family Review, 56(8), 739-763. https:// doi.org/10.1080/01494929.2020.1737624

[5] Hertlein, K. M., \& Ancheta, K. (2014). Clinical application of the advantages of technology in couple and family therapy. The American Journal of Family Therapy, 42(4), 313-324. https://doi.org/10.1080/01926187.2013.866511

[6] Fischer, C. S. (1992). America calling: A social history of the telephone to 1940. Berkeley: University of California Press. https://doi.org/10.1525/9780520915008

[7] Haythornthwaite, C. (2005). Social networks and internet connectivity effects. Information, Communication, \& Society, 8, 125-147. https://doi.org/10.1080/13691180500146185

[8] Jaser, E. (2013). Information and mobile technologies for promoting maternal-child health care status in rural areas of Jordan. International Journal of Interactive Mobile Technologies (iJIM), 7(3), 38-45. https://doi.org/10.3991/ijim.v7i3.2540

[9] Al-Emran, M., \& Salloum, S. A. (2017). Students' attitudes towards the use of mobile technologies in e-evaluation. International Journal of Interactive Mobile Technologies (IJIM), 11(5), 195-202. https://doi.org/10.3991/ijim.v11i5.6879

[10] Chesley, N., \& Johnson, B. (2010). Information and communication technology, work, and family. In S. Seet \& J. Chesley (eds.) Work and family encyclopedia. Chestnut Hill, MA: Slo a Work and Family Research Network. 
[11] Chaichitwanidchakol, P., \& Feungchan, W. (2020). Design and implementation of an interactive mobile application for autistic children in a physical education class. International Journal of Interactive Mobile Technologies, 14(14), 134. https://doi.org/10.3991/ijim. v14i14.15477

[12] Dew, J., \& Tulane, S. (2015). The association between time spent using entertainment media and marital quality in a contemporary dyadic national sample. Journal of Family and Economic Issues, 36(4), 621-632. https://doi.org/10.1007/s10834-014-9427-y

[13] Spencer, T. A., Lambertsen, A., Hubler, D. S., \& Burr, B. K. (2017). Assessing the mediating effect of relationship dynamics between perceptions of problematic media use and relationship satisfaction. Contemporary Family Therapy, 39(404), 80-86. https://doi.org/10.1007/ s10591-017-9407-0

[14] Hazan, C., \& Shaver, P. (1987). Romantic love conceptualized as an attachment process. Journal of Personality and Social Psychology, 52(3), 511-524. https://doi. org $/ 10.1037 / 0022-3514.52 .3 .511$

[15] Saare, M. A., Hussain, A., \& Yue, W. S. (2019). Conceptualizing mobile health application use intention and adoption among iraqian older adults: From the perspective of expanded technology acceptance model. International Journal of Interactive Mobile Technologies (iJIM), 13(10), 28-41. https://doi.org/10.3991/ijim.v13i10.11285

[16] International Telecommunications Union. (2009). Communications in Uganda: A look at one of Africa's fastest-growing markets. Retrieved from https://www.itu.int/net/itunews/ issues/2009/06/31.aspx on 5th August 2020

[17] Vicedo, M. (2011). The social nature of the mother's tie to her child: John Bowlby's theory of attachment in post-war America. The British Journal for the History of Science, 44(3), 401-426. https://doi.org/10.1017/S0007087411000318

[18] Bartholomew, K., \& Horowitz, L. M. (1991). Attachment styles among young adults: A test of a four-category model. Journal of Personality and Social Psychology, 61(2), 226-244. https://doi.org/10.1037/0022-3514.61.2.226

[19] Rumondor, P. C. B. (2019). Is There an application for improving marital satisfaction? an overview of smartphone usage in urban young adults' marital interactions. Makara Human Behavior Studies in Asia, 23(1), 97-112. https://doi.org/10.7454/hubs.asia.1190718

[20] Licoppe, C. (2004). Presence: The Emergence of a new repertoire for managing social relationships in a changing communication technoscape. Environment and Planning D: Society and Space, 22(1), 135-156. https://doi.org/10.1068/d323t

[21] Ogolsky, B. G., Monk, J. K., Rice, T. M., Theisen, J. C., \& Maniotes, C. R. (2017). Relationship maintenance: A review of research on romantic relationships. Journal of Family Theory \& Review, 9(3), 275-306. https://doi.org/10.1111/jftr.12205

[22] Chen, J., Hanrahan, B. V., Yuan, C. W., \& Carroll, J. M. (2018). Capturing community in mobility: Mobile methods for community informatics. Mobile Media \& Communication, 6(2), 163-178. https://doi.org/10.1177/2050157917730095

[23] Shin, D. H., Shin, Y. J., Choo, H., \& Beom, K. (2011). Smartphones as smart pedagogical tools: Implications for smartphones as u-learning devices. Computers in Human Behavior, 27(6), 2207-2214. https://doi.org/10.1016/j.chb.2011.06.017

[24] Chow, C. M., Claxton, S. E., \& van Dulmen, M. H. M. (2015). Testing dyadic mechanisms the right way: A primer into a moderated actor-partner interdependence model with latent variable interactions. Emerging Adulthood, 3(6), 421-433. https://doi. org/10.1177/2167696815605728 
[25] Papadakis, St. (2020). Robots and Robotics Kits for Early Childhood and First School Age. International Journal of Interactive Mobile Technologies (iJIM), 14(18), 34-56. https://doi. org/10.3991/ijim.v14i18.16631

[26] Dorouka, P., Papadakis, S., \& Kalogiannakis, M. (2020). Tablets and apps for promoting robotics, mathematics, STEM education and literacy in early childhood education. International Journal of Mobile Learning and Organisation, 14(2), 255-274. https://doi. org/10.1504/IJMLO.2020.106179; https://doi.org/10.1504/IJMLO.2020.10026334

[27] Kalogiannakis, M., \& Papadakis, S. (2020). The use of developmentally mobile applications for preparing pre-service teachers to promote stem activities in preschool classrooms. Mobile Learning Applications in Early Childhood Education, 82-100. https://doi.org/10.4018/978$\underline{1-7998-1486-3 . c h 005}$

[28] Palm, A. (2020). Mobile phone use and subjective well-being: Implications for responsible research and innovation. Working Papers on Innovation Studies, Centre for Technology, Innovation and Culture, University of Oslo.

[29] Hills, P., \& Argyle, M. (2002). The oxford happiness questionnaire: A compact scale for the measurement of psychological well-being. Personality and Individual Differences, 33(7), 1071-1082. https://doi.org/10.1016/S0191-8869(01)00213-6

[30] Olson, D. H., Fournier, D. G., \& Druckman, J. M. (1985). ENRICH: Enriching and Nurturing Relationships Issues, Communication, and Happiness.

[31] Diener, E. (1984). Subjective well-being. Psychological Bulletin, 95(3), 542-575. https:// doi.org/10.1037/0033-2909.95.3.542

[32] Mansoor, M., Awan, T. M., \& Syed, F. (2020). Positive emotions as an underlying mechanism between customer gratitude and behavioral intentions. Journal of Administrative and Business Studies, 6(1), 9-20. https://doi.org/10.20474/jabs-6.1.2

[33] Mansoor, M., Awan, T. M., \& Alobidyeen, B. (2020). Structure and measurement of customer experience management. International Journal of Business and Administrative Studies, 6(4), 171-182. https://doi.org/10.20469/ijbas.6.10001-4

[34] Dalle, J., Siyoto, S., Astika, N.D., Negara, J.N., Chandra, T., \& Anam, K. (2020). The moderating role of IT adoption and mechanism of dynamic capabilities on Indonesian pharmaceutical firms performance. Systematic Reviews in Pharmacy, 11(9), 982-992. https://repo-dosen.ulm.ac.id//handle/123456789/18232

[35] Akrim, M., \& Harfiani, R. (2019). Daily learning flow of inclusive education for early childhood | Flujo de aprendizaje diario de educación inclusiva para la niñez temprana. Utopia y Praxis Latinoamericana, 24(Extra6), 132-141.

[36] Katz, J. E, and Aakhus, M. (Eds.). (2002). Perpetual contact: Mobile communication, private talk, public performance. Cambridge: Cambridge University Press. https://doi.org/10.1017/ CBO9780511489471

[37] Mansoor, M., \& Noor, U. (2019). Determinants of Green Purchase Intentions: Positive Word of Mouth as moderator. Journal of Business \& Economics, 11(2), 143-160. http://111.68.96.103:40003/ojs/index.php/jbe/article/view/125

[38] Barclay, D., Higgins, C., \& Thompson, R. (1995). The partial least squares (PLS) approach to causal modeling: personal computer adoption and use as an Illustration.

[39] Yamamori, K. (2019). Classroom practices of low-cost STEM education using scratch. Journal of Advanced Research in Social Sciences and Humanities Volume, 4(6), 192-198. https://doi.org/10.26500/JARSSH-04-2019-0601 
[40] Luczak, C., \& Kalbag, A. (2018). The appropriateness and effectiveness of cross-aged peer mentoring in the learning environment. International Journal of Humanities, Arts and Social Sciences, 4(2), 76-84. https://doi.org/10.20469/ijhss.4.10003-2

[41] Hair, J. F., Ringle, C. M., \& Sarstedt, M. (2011). PLS-SEM: Indeed, a silver bullet. Journal of Marketing Theory and Practice, 19(2), 139-152. https://doi.org/10.2753/ MTP1069-6679190202

[42] Papadakis, S., Vaiopoulou, J., Kalogiannakis, M., \& Stamovlasis, D. Developing and Exploring an Evaluation Tool for Educational Apps (E.T.E.A.) Targeting Kindergarten Children. Sustainability 2020, 12, 4201. https://doi.org/10.3390/su12104201

[43] Drolia, M., Sifaki, E., Papadakis St., \& Kalogiannakis, M. (2020). An Overview of Mobile Learning for Refugee Students: Juxtaposing Refugee Needs with Mobile Applications' Characteristics. Challenges, 11(2), 31. https://doi.org/10.3390/challe11020031

\section{Authors}

Dr. A. Akrim is deputy rector public affairs and finance of Universitas of Muhammadiyah Sumatera Utara and lecturer in the Department of Islamic early childhood Education. Faculty of Islamic Religious. He received an undergraduate degree (S.Pd) in education from the University of Muhammadiiyah Sumatera Utara in 2003 and a Master's degree (M.Pd) in education obtained from State University of Medan in 2008 and a Doktor's Program in Islamic Education from State University Muhammadiyah of Malang in 2020.

Dr. Juhriyansyah Dalle is a lecturer at the Department of Information Technology Universitas Lambung Mangkurat, Banjarmasin Indonesia. He gained his master's degree in computer sciences from Universitas Gadjah Mada in 2003 and his Doctoral Degree from Universiti Utara Malaysia in 2010. His academic interest areas are Information studies, multimedia content, educational technology, and media. His expertise is human-computer interaction, usability, computers in education, information system development, and applied statistics in education and information technology. Email: j.dalle@ulm.ac.id.

Article submitted 2020-08-16. Resubmitted 2020-12-16. Final acceptance 2020-12-16. Final version published as submitted by the authors. 